\title{
Satisfaction Level of Inpatients on the Nursing Care Provided By Staff Nurses at King Fahd Central Hospital
}

\author{
${ }^{1}$ Ibrahim Al Neami ${ }^{2}$ Cynthia G. Dimabayao and ${ }^{3}$ Elizer R. Caculitan \\ ${ }^{1}$ Director of Training and Scholarship Administration,MOH,Gizan KSA \\ ${ }^{2}$ Asst. Professor, College of Nursing and Allied Health, Jazan University, Gizan KSA \\ ${ }^{3}$ Asst Professor, College of Applied Medical Sciences, Jazan University, Gizan KSA
}

\begin{abstract}
:
Objective: The main objective of this study is to obtain a comprehensive data on the satisfaction level of inpatients on the nursing care provided by staff nurses at King Fahd Central Hospital in order to improve and strengthen the efficiency of health services and upgrading the provision of nursing practice through appropriate training program.

Methodology: This is a descriptive- cross sectional study where 148 inpatients from eleven female wards/units at King Fahd Central Hospital were used. Data were gathered from them during the day of their discharge using a questionnaire adopted from Satisfaction with Care - SF (version 11/99) (www.promotingexcellence.org). However, the items were re-stated to suit the conditions in the setting of the study. A five-point Likert's scale was used. The weighted mean and Kendall Coefficient of Concordance were used to treat the data. The Chi-Square was used to determine whether or not there is significant correlation among the ranks showing the satisfaction level of inpatients. The null hypothesis was tested based on a 0.05 alpha level.

Findings: Inpatients from the FNW (4.31); ENT (3.80), and $O B$ (3.74) were very satisfied while those from other wards were just satisfied on the nursing care provided by the nursing staff to them during their stay in the hospital. Inpatients from the $O B$ (3.95) and FNW (3.71) were very satisfied on the services of nursing staff other than their work in the ward. It was only in Pedia-1 where the inpatients expressed they were unsatisfied (2.34). There was no significant correlation $\left(X_{2}=13.068 ; d f=11\right.$; 0.05 alpha level) of the ranks given by the inpatients on their level of satisfaction on the nursing care provided to them. There was also no significant correlation $\left(X^{2}=6.512 ; d f=4 ; 0.05\right.$ alpha level) on the ranks they gave on their level of satisfaction on the services of nurses other than the ward.

Conclusion: Generally, the inpatients were satisfied on the nursing care provided by the nursing staff. Their level of satisfaction on the services of the nursing staff in the wards/units and their other services showed no significant correlation. Implementation of the training program for staff nurses to improve their services is necessary to increase satisfaction level of inpatients.
\end{abstract}

Key words: Satisfaction Level, Inpatients, Nursing Care, Staff Nurses, Wards

\section{Introduction}

Nurses are group of healthcare professional who promote health, prevent diseases and save life. In today's healthcare environment, nurses must be ready to complete a comprehensive physical and mental assessment of patient. Nurses needs to possess specialized knowledge in the area in which they practice in order to develop their clinical competency. Moreover comprehensive knowledge of individual needs, personality and situation would be an asset for the nurse caring for the patient. These knowledge should be shared with colleagues, patient and patient significant others.

There are two extremely important attributes of an ideal nurse that is caring nature (Rush and Cook 2006) and serving people wholeheartedly (Davis et al, 1990).They should be compassionate and kind and show respect for others (Rush and Cook 2006).

An ideal nurse is confident and competent in providing safe care through skilled in leadership. Delivery of care is dependent upon nurses' personal qualities which will influence behavior in relation to delivery of care. Behavior of nurses plays an important role including strong communication skills being accessible and working well with a team.

Hospitals are institutions that provide health care to the sick and promote the wellness of people. Their sizes depend on the population in the service area as well as the budget allocated for it. Their services are varied to meet the kind of health problem of any client. Hospitals also differ in the availability of facilities and this determines also the services it provides. Whether a hospital is big or small, the organizational set-up is practically the same. There are medical teams who are the primary employees. There are also managerial and support staffs who have medical education backgrounds, too. They work together to attain the vision, mission 
and goals of the hospital aside from the performance of their roles as medical or health workers. With this end in view, it brings satisfaction to the patients.

Among the health workers in a hospital, the nurses have more patient interactions than any other group (www.fletcherallen.org). The nurses may have an area of specialization, but they are expected to give service in various setting and units in the hospital. Thus, the core of the staff nurses' job is to provide nursing care to those who need it (Montago, http://ezinearticles.com). Among the clinical activities of nurses (www.medicalgeek.com) are:

- Arrives on time and takes handover of patient from bed to bed;

- Carries out assigned jobs given by sister/ward in charge;

- Plans and provides the basic care according to the priority needs of the patients;

- Prepares and takes round with the doctor;

- Carries out instructions appropriately like collection of specimens and medications among others;

- Maintains personal hygiene of patient to prevent infection; takes responsibility of admission and discharge of patient; and

- Maintains interpersonal relationship with staff, patients, families and communities.

With these responsibilities of the nurse as cited above, there is a possibility for them to burnout. Hence, the quality of care they provide to in-patients particularly might be affected. The study by Havey, et al. (2004) in 20 urban hospitals in the United States showed that the overall level of nurse burnout on hospital units affected patient satisfaction. They attributed this to the shortage of staff nurses. With this, they recommended improvements in nurses' work environment to reduce nurses' high levels of burnout with the view of increasing patients' satisfaction.

Alasad and Ahmad (2003) cited Ryden, et al. the seven dimensions as crucial in the measurement of patients' satisfaction. These are:

- Respect for patients' values, preference and expressed needs;

- Coordination, integration and information flow;

- Information and education;

- Physical comfort;

- Emotional support and alleviation of fear and anxiety;

- Involvement of family and friends; and

- Transition and continuity.

They addressed these dimensions in their study among 266 in-patients from the medical, surgical and gynecologicalwards of in Jordan. They found out that patients in the surgical wards had lower level of satisfaction compared to the patients in the medical and gynecological wards.

The study by Sen (2009) sought the patients' satisfaction towards health care services in a heart hospital. He found out that the patients were satisfied with the various service parameters of the hospital particularly on ambulance service, behavior of reception people, nursing care service, laundry service, behavior of IPD staff, security service, pharmacy service, comfort service, food service and business services.

The level of satisfaction among patients admitted with traumatic brain injury at an advanced ER/casualty in a tertiary teaching hospital in India was studied by Prasad, et al. (2013). They revealed that the satisfaction level of the patients was most of the time ranging from good to excellent. They reported to have no average or poor responses.

The study by Al-nasser and Mohamed (2013) was focused on 199 patients who underwent surgery at Sohag University Hospital. They determined patient satisfaction with preoperative care and its relationship with patient characteristics. They said that nearly a quarter of the patients were highly satisfied with preoperative care. Lack of preoperative surgical information and guidance, fear from undesirable outcomes, poor staff-patient relationship, low quality services, and some socio-demographic characteristics were found to affect patients' satisfaction.

Al Momani and Al Korashy (2012) conducted a cross-sectional survey within a three-month period among 448 patients admitted at King Khalid Teaching Hospital in Riyadh, Saudi Arabia. They used a 42-items questionnaire assessing six dimension of the nursing care provided during hospitalization. Using a four-point scale, they found out that nursing care with lowest mean were on the information received from the nurses about self-help; the information about the laboratory results and the way the nurse shared the patient's feelings.

Another study on inpatients satisfaction with nursing services at King Khalid University Hospital in Riyadh was made by Al-Doghaither (2000) among 450 inpatients from different wards. He found out that the lowest score was on communication items as shown by limited communication between nurses and patients which he attributed to cultural and language barriers; there was no proper oversight of patients' personal hygiene. The male patients were mostly dissatisfied with most of the nursing care provided to them. 
The quality of patient care provided by staff nurses enables the client and significant others to gain confidence that the sick will recover very soon. Somehow, it showcases the quality of care given by the staff nurses in particular and the hospital in general.

It can be gleaned from the literature review that there were varied levels of satisfaction on inpatients. This is due to differences in setting and research instruments used. While it is true that improving nursing services were recommended by them, not one made an actual training design for staff nurses to improve patients' satisfaction. This is what the present study tries to bridge.

\section{Objectives}

This study aims to obtain a comprehensive data on the satisfaction level of inpatients on the nursing care provided to them and to design an in-service training program for staff nurses to improve the services of staff nurse which will eventually increase patients' satisfaction.

\section{Methodology}

This is a descriptive cross-sectional study where 148 inpatients from eleven female wards/units at King Fahd Central Hospital in Jazan, Kingdom of Saudi Arabia were respondents. Data were taken from them during the day of their discharge using a questionnaire adopted from Satisfaction with Care - SF (version11/99) (www.promotingexcellence.org). However, the items were re-stated to suit the conditions in the setting. Data collection was done for a period of one week. A five-point Likert's scale was used where: 1 - Poor/Very much unsatisfied; 2- Fair/Unsatisfied; 3- Good/Satisfied; 4- Very Good/Very Satisfied; and 5- Excellent/Very much satisfied.

The Weighted Mean, and Kendall Coefficient of Concordance were used to treat the data. The ChiSquare was used to determine whether or not there is significant correlation among the ranks showing the satisfaction level of the inpatients. The null hypothesis was tested based on a 0.05 alpha level.

\section{Results}

Presentation of the results of this study comes in three parts. These are on the satisfaction level of the inpatients about the services of the staff nurses in the female ward/unit; satisfaction level of the same patients on other services of these nurses other than their services in the ward/unit; and the values of correlation of the ranks across wards.

Satisfaction level of inpatients on the services of staff nurses in the ward/unit. The quantified results shown in Table 1 reveals the level of satisfaction regarding the services of the nurses carried out in the ward/unit. In the Female Orthopedic Ward (FOW), the indicator with highest rating was on the way the nurses carried out physical examination like vital signs $(\mathrm{Wm}=3.40)$ which means "Good". The indicators which received the lowest rating were the promptness of nurses in answering buzzer calls and the time devoted to the patients. With a weighted mean value of 2.16, this means that these services of the nurses were "Fair". As a whole, the inpatients in the FOW rated the nurses' services as good $(\mathrm{Mw}=2.70)$. This shows that the inpatients in this ward were satisfied with the services of the nurses.

As to the inpatients in the Delivery Room (DR), the indicator where they gave the highest rating was on the way the nurses carried out physical examination ( $\mathrm{Wm}=3.52)$ which is "very good". Two indicators were also noted to have lowest rating. These were attention given to the comfort of the patient and the time devoted by nurses to them $(\mathrm{Wm}=2.91)$. This is on the level of "good". When the overall mean was determined it yielded a value of 3.1 which means "good". This means that the inpatients in the DR were satisfied with the services of the nurses who attended to them.

In the Burns unit, the primary indicator which gave the inpatients a very good satisfaction was on the way the nurses carried out physical examination $(\mathrm{Wm}=3.52)$. The indicator with lowest weighted mean value was on the information they gave about medical tests $(\mathrm{Wm}=2.76)$ where they considered "good". The overall mean obtained from their responses was $\mathrm{Wm}=3.11$ which means good showing that the inpatients in this unit were satisfied by the services of the nurses to them.

As to the inpatients in the FMW, it was noted that they were very satisfied with the attention given by the nurses to their comfort $(\mathrm{Wm}=3.60)$. The lowest weighted mean value was on the information they gave about the treatment of the patient $(\mathrm{Wm}=2.55)$. This, however, shows that they were satisfied with the services given by the nurses to them. Generally, the inpatients in the FMW were satisfied with the nurses' services as evidenced by the overall mean value of 3.20 .

In the OB ward, two indicators were found to have highest rating. These were on the way the nurses carried out physical examination and on the nurses' personal qualities like politeness, respect, sensitivity, kindness and patience $(\mathrm{Wm}=4.29)$. This shows that the inpatients in this ward were very satisfied on these indicators. These inpatients gave the lowest rating on the promptness of nurses in answering buzzer calls 
$(\mathrm{Wm}=3.12)$. When the overall mean of their rating were calculated, it yielded an overall mean value of 3.74 which means that the patients in this ward were very satisfied on the services given by the nurses to them.

Table 1 Satisfaction Level Of Inpatients On Nursing Care In The Different Wards/Units

\begin{tabular}{|c|c|c|c|c|c|c|c|c|c|c|c|c|c|}
\hline \multirow[b]{2}{*}{ No. } & \multirow[b]{2}{*}{ Indicators } & \multicolumn{2}{|c|}{ FOW } & \multicolumn{2}{|l|}{ DR } & \multicolumn{2}{|c|}{ Burns } & \multicolumn{2}{|c|}{ FMW } & \multicolumn{2}{|l|}{ OB } & \multicolumn{2}{|c|}{ Pedia-2 } \\
\hline & & $\mathrm{Wm}$ & $\mathrm{R}$ & $\mathrm{Wm}$ & $\mathrm{R}$ & $\mathrm{Wm}$ & $\mathrm{R}$ & $\mathrm{Wm}$ & $\mathrm{R}$ & $\mathrm{Wm}$ & $\mathrm{R}$ & $\mathrm{Wm}$ & $\mathrm{R}$ \\
\hline 1 & $\begin{array}{l}\text { Carrying out physical } \\
\text { examination (e.g. taking of } \\
\text { vital signs). }\end{array}$ & 3.40 & 12 & 3.41 & 12 & 3.52 & 12 & 3.25 & 5 & 4.29 & 11.5 & 3.46 & 12 \\
\hline 2 & Administration of medications. & 3.04 & 9 & 3.14 & 7.5 & 3.33 & 11 & 3.40 & 10 & 3.76 & 8.5 & 2.62 & 4 \\
\hline 3 & $\begin{array}{l}\text { Attention given to comfort of } \\
\text { patient. }\end{array}$ & 3.08 & 10 & 2.91 & 1.5 & 3.10 & 7 & 3.60 & 12 & 4.24 & 10 & 3.0 & 9.5 \\
\hline 4 & $\begin{array}{l}\text { Willingness to listen to } \\
\text { patients' concerns. }\end{array}$ & 2.36 & 3 & 3.05 & 5.5 & 2.81 & 2 & 3.20 & 4 & 3.53 & 4 & 2.92 & 6.5 \\
\hline 5 & $\begin{array}{l}\text { Personal interest shown to } \\
\text { patient. }\end{array}$ & 2.88 & 8 & 3.05 & 5.5 & 3.10 & 7 & 3.40 & 10 & 3.65 & 6.5 & 3.38 & 11 \\
\hline 6 & $\begin{array}{l}\text { Comfort and support given to } \\
\text { patient. }\end{array}$ & 3.16 & 11 & 3.18 & 9 & 3.05 & 4 & 3.35 & 7 & 3.41 & 2 & 3.0 & 9.5 \\
\hline 7 & $\begin{array}{l}\text { Personal qualities of nurses like } \\
\text { politeness, respect, sensitivity, } \\
\text { kindness and patience. }\end{array}$ & 2.72 & 7 & 3.23 & 10.5 & 3.24 & 9.5 & 3.40 & 10 & 4.29 & 11.5 & 3.62 & 4 \\
\hline 8 & $\begin{array}{l}\text { Information given to patients } \\
\text { about medical tests. }\end{array}$ & 2.64 & 6 & 3.0 & 4 & 2.76 & 1 & 2.70 & 1 & 3.65 & 6.5 & 2.15 & 2 \\
\hline 9 & $\begin{array}{l}\text { Information given to patients } \\
\text { about routine patient care. }\end{array}$ & 2.40 & 4 & 3.14 & 7.5 & 3.10 & 7 & 2.85 & 3 & 3.47 & 3 & 1.92 & 1 \\
\hline 10 & $\begin{array}{l}\text { Information to patients about } \\
\text { treatments. }\end{array}$ & 2.44 & 5 & 3.23 & 10.5 & 3.05 & 4 & 2.55 & 2 & 3.76 & 8.5 & 2.62 & 4 \\
\hline 11 & $\begin{array}{l}\text { Promptness of nurses in } \\
\text { answering buzzer calls. }\end{array}$ & 2.16 & 1.5 & 2.95 & 3 & 3.05 & 5 & 3.35 & 7 & 3.18 & 1 & 2.92 & 6.5 \\
\hline 12 & Time devoted to patients. & 2.16 & 1.5 & 2.91 & 1.5 & 3.24 & 9.5 & 3.35 & 7 & 3.59 & 5 & 2.77 & 8 \\
\hline & Overall Mean & \multicolumn{2}{|c|}{2.70} & \multicolumn{2}{|c|}{3.10} & \multicolumn{2}{|c|}{3.11} & \multicolumn{2}{|c|}{3.20} & \multicolumn{2}{|c|}{3.74} & \multicolumn{2}{|c|}{2.87} \\
\hline & Rank of Overall Mean & \multicolumn{2}{|c|}{1} & & & & & \multicolumn{2}{|c|}{3} \\
\hline \multicolumn{2}{|r|}{ Interpretation of Overall Mean } & \multicolumn{2}{|c|}{$\mathbf{S}$} & & & \multicolumn{2}{|l|}{5} & \multicolumn{2}{|c|}{ VS } & \\
\hline
\end{tabular}

Legend: FOW - Female Orthopedic Ward

DR - Delivery Room

FMW - Female Medical Ward

FHDU - Female Homodialysis Unit

ENT - Eye, Nose, Throat

CCU - Coronary care Unit
1 - Poor/Very Unsatisfied

2 - Fair/Unsatisfied

3 - Good/Satisfied

4 - Very Good/Very Satisfied

5 - Excellent/Very Much Satisfied

Table 1, cont.

\begin{tabular}{|c|c|c|c|c|c|c|c|c|c|c|c|c|c|c|}
\hline No. & Indicators & \multicolumn{2}{|c|}{ Pedia-1 } & \multicolumn{2}{|c|}{ FNW } & \multicolumn{2}{|c|}{ FHDU } & \multicolumn{2}{|c|}{ ENT } & \multicolumn{2}{|c|}{$\mathrm{CCU}$} & $\begin{array}{l}\text { Overal } \\
1 \text { Mean }\end{array}$ & $\begin{array}{l}\text { Ran } \\
\mathrm{k}\end{array}$ & Int. \\
\hline 1 & $\begin{array}{l}\text { Carrying out physical examination (e.g.t taking vital } \\
\text { signs). }\end{array}$ & 3.30 & 11 & 4.29 & 5.5 & 3.17 & 9.5 & 3.60 & 4 & 3.0 & 7 & 3.52 & 12 & vs \\
\hline 3 & Attention given to comfort of patient. & 3.10 & 8.5 & 4.71 & 10.5 & 3.17 & 9.5 & 3.60 & 4 & 3.0 & 7 & 3.41 & 10 & $\mathbf{S}$ \\
\hline 4 & Willingness to listen to patients' concems. & 3.0 & 6 & 4.71 & 10.5 & 3.0 & 4 & 3.60 & 4 & 2.50 & 1.5 & 3.15 & 4 & $\mathrm{~S}$ \\
\hline 5 & Personal interest shown to patient. & 3.10 & 8.5 & 4.71 & 10.5 & 3.0 & 4 & 3.60 & 4 & 2.50 & 1.5 & 3.31 & 8 & $\mathbf{S}$ \\
\hline 8 & Information given to patients about medical tests. & 1.90 & 1 & 3.71 & 1 & 3.0 & 4 & 3.40 & 1 & 3.50 & 12 & 2.95 & 1 & $\mathbf{S}$ \\
\hline 9 & Information to patients about routine patient care. & 2.10 & 2 & 4.0 & 3 & 3.0 & 4 & 4.20 & 11 & 3.0 & 7 & 3.02 & 2 & $\mathrm{~s}$ \\
\hline 10 & Informationto patients about treatments. & 2.20 & 3 & 3.86 & 2 & 3.0 & 4 & 4.0 & 9.5 & 3.0 & 7 & 3.06 & 3 & $\mathbf{S}$ \\
\hline 11 & Promptness of nurses in answering buzzer calls. & 2.80 & 5 & 4.29 & 5.5 & 3.33 & 12 & 3.80 & 7.5 & 3.0 & 7 & 3.17 & 5 & $\mathbf{S}$ \\
\hline 12 & Time devoted to patients. & 3.10 & 8.5 & 4.71 & 10.5 & 3.0 & 4 & 3.80 & 7.5 & 3.0 & 7 & 3.24 & 6 & $\mathbf{S}$ \\
\hline \multicolumn{2}{|r|}{ Overall Mean } & \multicolumn{2}{|c|}{2.80} & \multicolumn{2}{|c|}{4.31} & \multicolumn{2}{|c|}{3.08} & \multicolumn{2}{|c|}{3.80} & \multicolumn{2}{|c|}{2.96} & \multicolumn{2}{|c|}{3.25} & $\mathrm{~S}$ \\
\hline
\end{tabular}

In Pedia-2, the mothers of the inpatients were very satisfied $(\mathrm{Wm}=3.62)$ on the personal qualities of the nurses. They were unsatisfied $(\mathrm{Wm}=1.92)$ about information they gave about routine patient care. The overall mean of 2.87, however, shows that the mothers of the inpatients in this ward satisfied.

In Pedia-1, the mothers of the inpatients were also very satisfied $(\mathrm{Wm}=3.40)$ on the personal qualities of the nurses. However, they were unsatisfied $(\mathrm{Wm}=1.9)$ on the information given to them about medical tests. As a whole, they were satisfied $(\mathrm{Wm}=2.8)$ with the services of the nurses in this ward.

There were four indicators which were noted with highest rating equivalent to "Excellent" in FNW. These means that the inpatients there were very much satisfied with the attention given to their comfort; their willingness to listen to all their concerns; the personal interest they have shown to them as patients, and the time 
devoted by the nurses to them. It can be noticed that even the indicator with lowest rating still shows that the inpatients were very satisfied. This was on the information they gave about medical tests $(\mathrm{Wm}=3.71)$. The overall mean obtained was 4.31 which mean that the inpatients were very satisfied with the services given by the nurses.

In the hemodialysis unit (FHDU), the highest rating was given on the promptness of nurses in answering buzzer calls $(\mathrm{Wm}=3.33)$ which shows that the inpatients were satisfied on this. Several indicators shared the same the lowest rating of $\mathrm{Mw}=3.0$. These were on administration of medications; willingness to listen to patients' concerns; personal interest shown to patient; information given to patients about medical tests; information to patients about routine patient care; information to patients about treatments; and promptness of nurses in answering buzzer calls. The overall mean of responses in this unit is 3.08 which means that the inpatients were satisfied on the services of the nurses.

The personal qualities of the nurses was the indicator which the inpatients in the ENT gave the highest rating $(\mathrm{Wm}=4.40)$ which means they that they were very much satisfied. The indicator with lowest rating was on the information given to patients about medical tests $(\mathrm{Wm}=3.40)$. This shows that they were satisfied on this service. Generally, however, the inpatients in the ENT were very satisfied on the services rendered to them by the nurses.

In the CCU, the inpatients were very satisfied about the information given to them about medical tests. However, they satisfied only on the willingness of nurses to listen to patients' concerns and on the personal interest shown to patient $(\mathrm{Wm}=2.50)$. The overall mean of 2.96 on the responses of the inpatients in this unit shows that they were satisfied.

Summarizing all the responses of the respondents in the wards/units taken in the study, it appears that that the inpatients were very satisfied on two indicators only. These were on carrying out physical examination $(\mathrm{Wm}=3.52)$ and on the personal qualities of the nurses $(\mathrm{Wm}=51)$. In terms of wards/units, the inpatients from the OB $(\mathrm{Wm}=3.74)$; FNW $(\mathrm{Wm}=4.31)$ and $\mathrm{ENT}(\mathrm{Wm}=3.80)$ were very satisfied.

Satisfaction level of inpatients on other services of staff nurses. Table 2 shows the rating given by the inpatients about the services of the staff nurses other than the ward. It can be noted that the inpatients FOW gave highest rating on the information provided by nurse upon admission $(\mathrm{Wm}=3.16)$ which means they were satisfied. They were unsatisfied with the speed in providing information about medical tests results and/or treatments. As a whole, these group of inpatients were satisfied on the services of nurses $(\mathrm{Wm}=2.79)$.

Table 2 Satisfaction Level Of Inpatients On Other Services Provided By Staff Nurses

\begin{tabular}{|c|c|c|c|c|c|c|c|c|c|c|c|}
\hline \multirow[b]{2}{*}{ No. } & \multirow[b]{2}{*}{ Indicators } & \multicolumn{2}{|c|}{ FOW } & \multicolumn{2}{|c|}{ DR } & \multicolumn{2}{|c|}{ Burns } & \multicolumn{2}{|c|}{ FMW } & \multicolumn{2}{|c|}{ Pedia-2 } \\
\hline & & $\mathrm{Wm}$ & $\mathrm{R}$ & $\mathrm{Wm}$ & $\mathrm{R}$ & $\mathrm{Wm}$ & $\mathrm{R}$ & $\mathrm{Wm}$ & $\mathrm{R}$ & $\mathrm{Wm}$ & $\mathrm{R}$ \\
\hline 1 & $\begin{array}{l}\text { Exchange of information among health } \\
\text { team } \\
\text { (nurse/doctor/medtech/radiologist,etc.). }\end{array}$ & 2.80 & 3 & 3.0 & 3 & 2.90 & 3 & 2.85 & 4 & 2.69 & 2 \\
\hline 2 & $\begin{array}{l}\text { Kindness and helpfulness of the nurse in } \\
\text { assisting patient to the laboratories and } \\
\text { other hospital personnel. }\end{array}$ & 2.48 & 2 & 3.05 & 4 & 3.10 & 5 & 3.15 & 5 & 2.46 & 3 \\
\hline 3 & Information provided upon admission. & 3.16 & 5 & 2.85 & 2 & 3.05 & 4 & 2.40 & 1 & 3.38 & 4.5 \\
\hline 4 & Information provided upon discharge. & 3.12 & 4 & 2.82 & 1 & 2.52 & 1 & 2.45 & 2 & 3.38 & 4.5 \\
\hline 5 & $\begin{array}{l}\text { Speed in providing information about } \\
\text { medical tests/treatments. }\end{array}$ & 2.40 & 1 & 3.09 & 5 & 2.67 & 2 & 2.50 & 3 & 2.08 & 1 \\
\hline & Overall Mean & \multicolumn{2}{|c|}{2.79} & \multicolumn{2}{|c|}{2.92} & \multicolumn{2}{|c|}{2.85} & \multicolumn{2}{|c|}{2.67} & \multicolumn{2}{|c|}{2.80} \\
\hline & Rank of Overall Mean & \multicolumn{2}{|c|}{3} & \multicolumn{2}{|c|}{8} & \multicolumn{2}{|c|}{5} & \multicolumn{2}{|c|}{2} & \multicolumn{2}{|c|}{4} \\
\hline & Interpretation of Overall Mean & \multicolumn{2}{|c|}{ Satisfied } & \multicolumn{2}{|c|}{ Satisfied } & \multicolumn{2}{|c|}{ Satisfied } & \multicolumn{2}{|c|}{ Satisfied } & \multicolumn{2}{|c|}{ Satisfied } \\
\hline
\end{tabular}

Table 2, cont.

\begin{tabular}{|c|c|c|c|c|c|c|c|c|c|c|c|c|}
\hline \multirow{3}{*}{ No } & \multirow{3}{*}{ Indicators } & \multirow{2}{*}{\multicolumn{2}{|c|}{ Pedia-1 }} & & & & & \multirow{2}{*}{\multicolumn{2}{|c|}{ ENT }} & \multirow{2}{*}{\multicolumn{2}{|c|}{$\begin{array}{c}\text { Overall } \\
\text { Mean }\end{array}$}} & \\
\hline & & & & \multicolumn{2}{|c|}{ FNW } & \multicolumn{2}{|c|}{ FHDU } & & & & & \multirow[t]{2}{*}{ Int. } \\
\hline & & $\mathrm{Wm}$ & $\mathrm{R}$ & $\mathrm{Wm}$ & $\mathrm{R}$ & $\mathrm{Wm}$ & $\mathrm{R}$ & $\mathrm{Wm}$ & $\mathrm{R}$ & $\mathrm{Wm}$ & $\mathrm{R}$ & \\
\hline 1 & $\begin{array}{l}\text { Exchange of information among } \\
\text { health team } \\
\text { (nurse/doctor/medtech/radiologist/etc. } \\
\text { ). }\end{array}$ & 3.10 & $\begin{array}{r}4 . \\
5\end{array}$ & 3.86 & 3.5 & 3.0 & 3.5 & 2.80 & 1 & 3.06 & 3.5 & S \\
\hline 2 & $\begin{array}{l}\text { Kindness and helpfulness of the nurse } \\
\text { I assisting patient to the laboratories } \\
\text { and other hospital personnel. }\end{array}$ & 3.10 & $\begin{array}{r}4 . \\
5\end{array}$ & 4.14 & 5 & 3.0 & 3.5 & 3.60 & 4.5 & 3.19 & 5 & $\mathrm{~S}$ \\
\hline 3 & Information provided upon admission. & 1.90 & 2 & 3.29 & 1.5 & 3.0 & 3.5 & 3.20 & 3 & 3.05 & 2 & $\mathrm{~S}$ \\
\hline 4 & Information provided upon discharge. & 2.10 & 3 & 3.86 & 3.5 & 2.5 & 1 & 3.60 & 4.5 & 3.06 & 3.5 & $\mathrm{~S}$ \\
\hline 5 & $\begin{array}{l}\text { Speed in providing information about } \\
\text { medical tests/treatments. }\end{array}$ & 1.4 & 1 & 3.29 & 1.5 & 3.0 & 3.5 & 3.0 & 2 & \multirow{2}{*}{\multicolumn{2}{|c|}{\begin{tabular}{c|c}
2.68 & 1 \\
3.01
\end{tabular}}} & $\mathrm{~S}$ \\
\hline & Overall Mean & \multicolumn{2}{|c|}{2.32} & \multicolumn{2}{|c|}{3.71} & \multicolumn{2}{|c|}{2.90} & \multicolumn{2}{|c|}{3.24} & & & $\mathrm{~S}$ \\
\hline & Rank of Overall Mean & \multicolumn{2}{|c|}{1} & \multicolumn{2}{|c|}{10} & \multicolumn{2}{|c|}{6.5} & \multicolumn{2}{|c|}{9} & \multirow{2}{*}{\multicolumn{3}{|c|}{ Satisfied }} \\
\hline & Interpretation of Overall Mean & $\begin{array}{r}\text { Unsat } \\
\mathrm{d}\end{array}$ & & $\begin{array}{l}\text { Very } \\
\text { Unsati }\end{array}$ & & Satis & & Sati & & & & \\
\hline
\end{tabular}


As to the inpatients admitted at the DR, their highest rating of satisfaction was on the speed in providing information about medical tests and/or treatments $(\mathrm{Wm}=3.09)$. The information about discharge $(\mathrm{Wm}=2.82)$ was the service with lowest rating they gave. Generally, however, the inpatients in the DR were satisfied on the services of the nurses aside from their work in the ward. This is evidenced by $\mathrm{Wm}=2.92$.

In the Burns unit, the inpatients indicated their highest satisfaction rating on the kindness and helpfulness of the nurses in assisting them in the laboratories and other hospital personnel $(\mathrm{Wm}=3.10)$. The lowest rating was on information provided upon discharge $(\mathrm{Wm}=2.52)$. These inpatients were generally satisfied $(\mathrm{Wm}=2.85)$ on the services of the staff nurses.

Inpatients in FMW were also generally satisfied ( $\mathrm{Wm}=2.67)$ about the services of the staff nurses other that their services in the ward. They gave the highest satisfaction rating the kindness and helpfulness of nurses in assisting them in the laboratories and other hospital personnel $(\mathrm{Wm}=3.15)$. the lowest rating was on information provided upon admission $(\mathrm{Wm}=2.52)$.

In the $\mathrm{OB}$ ward, it was found out that all the indicators received rating showing that the inpatients were very satisfied $(\mathrm{Wm}=3.95)$. The highest rating was on information provided upon discharge $(\mathrm{Wm}=4.35)$ while the lowest rating was on speed in providing information about medical tests and/or treatments.

Generally, the inpatients in Pedia-2 ward were satisfied $(\mathrm{Wm}=2.80)$. Highest rating of satisfaction was on information provided upon admission and upon discharge. Both of these have a weighted mean value of 3.38 .

In Pedia-1 ward, however, the inpatients were generally unsatisfied $(\mathrm{Wm}=2.32)$. They were only satisfied on two indicators. These were on exchange of information among the health team which include the nurse and on the kindness and helpfulness of nurses in assisting patients in the laboratories and other hospital personnel $(\mathrm{Wm}=3.10)$. The rest of the ratings showed that they were unsatisfied, the lowest of which was on speed in providing information about medical tests and/or treatments $(\mathrm{Wm}=1.40)$.

The inpatients in FNW, as a whole, were very satisfied with the services of the staff nurses ( $\mathrm{Wm}=3.71)$. In particular, they were very satisfied on the kindness and helpfulness of the nurses in assisting them in the laboratories and other hospital personnel $(\mathrm{Wm}=4.14)$. Two indicators satisfied the inpatient only and these were on information provided upon admission and speed in providing information about medical tests and/or treatments. Both of these have a weighted mean value of 3.29.

All the indicators regarding services of the staff nurses in the FHDU other than their services in the ward/unit were found to almost have the same numerical rating $(\mathrm{Wm}=3.0)$. It was only on the rating for information provided upon discharge which was note to be lower $(\mathrm{Wm}=2.5)$. This means that the inpatients here were satisfied on the services of the nurses.

In the ENT, two indicators were very satisfactory among the inpatients. These were on kindness and helpfulness of nurses in assisting them in the laboratories and other hospital personnel and on information provided upon discharge. Both of these have a weighted mean value of 3.60. The lowest rating was on exchange of information among health team including the nurse $(\mathrm{Wm}=2.80)$. As a whole, inpatients in this unit were satisfied $(\mathrm{WM}=3.24)$ on the services of the nurses.

In the $\mathrm{CCU}$, the ratings were almost on the same level $(\mathrm{Wm}=3.0)$ showing that the inpatients were satisfied. It was only on information provided upon discharge which had a lower rating $(\mathrm{Wm}=2.50)$. with an overall weighted mean value of 2.90 , this means that the inpatients were satisfied with the services of the nurse other than those which they provide in the ward/unit.

Summarizing the ratings given by the respondents, it could be gleaned from the table that in terms of indicators, all of them satisfied the inpatients. The highest was on the kindness of the nurses in assisting the patients in laboratories and other hospital personnel $(\mathrm{Wm}=3.06)$. In terms of ward/unit, the inpatients from the $\mathrm{OB}$ ward $(\mathrm{Wm}=3.95)$ and FNW $(\mathrm{Wm}=3.71)$ were very satisfied.

Correlation of the ranks on the satisfaction level of inpatients across wards/units. Table 3 shows the values obtained when correlation of ranks on the satisfaction level of the inpatients across wards/units was determined. The calculation is shown in AppendicesB and C.

Apparently, the data show that the value of concordance (W) of ranks on the satisfaction level of inpatients on the services of staff nurses in the wards/units as well as their other services is low $(0.108$ and 0.148 respectively). When significance of correlation was determined using the Chi-Square, it yielded a $X^{2}=13.068$ for services of staff nurses in the wards in the wards/units while $X^{2}=6.512$ for other services. These values are lower than the critical values based on a 0.05 level of significance using their degrees of freedom. Thus, there is no significant correlation of ranks of the satisfaction level of the inpatients on the services of the staff nurses in the wards/units as well as on their other services. This means that the satisfaction level of inpatients in the different wards/units on the services of staff nurses stands independent from one another. The manner by which the indicators used to measure satisfaction level of inpatients were experienced by them in different intensity. Hence, there is no significant correlation. 
Table 3 Correlation of the Ranks on the Satisfaction Level of Inpatients Across Wards/Unit

\begin{tabular}{|c|c|c|}
\hline \multicolumn{1}{|c|}{ Services of staff Nurses in the Ward/Unit } & B. & Other Services of Staff Nurses \\
\hline Measure & Statistical Value & Statistical Value \\
\hline Number of groups $(\mathrm{m})$ & 11 & 11 \\
\hline Number of items correlated $(\mathrm{N})$ & 12 & 5 \\
\hline Sum of Ranks Squared $\left(\sum \mathrm{Tj}^{2}\right)$ & 64103 & 5624.5 \\
\hline Value of Concordance $(\mathrm{W})$ & 0.108 & 0.148 \\
\hline Chi-Square Value $\left(\mathrm{X}^{2}\right)$ & 13.068 & 6.512 \\
\hline Degree of Freedom $(\mathrm{df})$ & 11 & 4 \\
\hline Critical Value $(0.05 \alpha)$ & 19.68 & 9.49 \\
\hline Analysis & No significant correlation & No significant correlation \\
\hline
\end{tabular}

\section{Discussion}

Services provided by staff nurses in the wards/units seem not rigid. This is evidenced by the highest ratings given for basic work which is carrying out physical examination like taking vital signs. This is followed by their personal qualities like politeness, respect, sensitivity, kindness and patience. These two indicators made the inpatients very satisfied. The more rigorous responsibilities of nurses are on the satisfactory level only. This finding is in agreement with the findings of Havey, et al. (2004) that satisfaction is affected by burnout due to shortage of nurses. As to the case of King Fahd Central Hospital as a tertiary hospital and a training hospital as well, a better performance of staff nurses is desired to provide higher level of satisfaction among patients. However, the hospital admits plenty of patients and the staff nurses on duty might have been stressed so much. There are still other studies where patients generally were satisfied on the services of nurses like that of Alnasser and Mohamed(2013) that only nearly a quarter of the number of patients expressed satisfaction with the preoperative care they received from staff nurses.

The results also showed that the items concerning information or communication received the lowest ratings. Although they were satisfied, much is still desired by the patients. This is supported by the study of $\mathbf{A l}$ Momani and Al Khorashy (2012) undertaken in King Khalid Teaching Hospital in Riyadh, KSA. They revealed that information about laboratory results and information about self-help received the lowest mean. Similarly, the study by Al-Doghaither (2000) at King Khalid University Hospital in Riyadh also found out that lowest scores were on communication items and he attributed this to limited communication due to language barriers. It is a fact that many staff nurses in the kingdom are foreigners mostly from Asia who are non-Arabic speaking. Though they have learned some Arabic words commonly used in social conversation, yet it could not compensate to fully satisfy the patients' queries or right to be informed. Thus, some of the rights of the patients are affected especially relative to information.

Since there is not significant correlation among the ranks of the indicators used to measure satisfaction level of inpatients, it implies that staff nurses should be adaptive to the nature of patient care and situations in the wards/units they are assigned. Knowledge of individual differences plays a very important role in this case. Though it is difficult to please everyone, it is necessary to reduce the level of anxietyamong the patients. This will enable the staff nurse to think of better and more appropriate interventions or plans of nursing care.

\section{Conclusions}

From the foregoing findings, it is concluded that the inpatients from the wards/units used in this study were generally satisfied with the services provided by the staff nurses. There is no significant correlation among the ranks showing the satisfaction level of the inpatients on the services provided by the staff nurses. Implementation of the proposed training program to improve services of staff nurses is desired to eventually increase inpatients satisfaction.

\section{Proposed Training Program to Improve the Services of Staff Nurses to Eventually Increase Patients' Satisfaction}

This proposed training program is a product of the findings of the study. It covers five topics which can be implemented in one day and repeated on other days to accommodate attendance of all concerned. The proposed training program shows the structure and topics to be provided to the participants. 
A. Organizer/ Convenor: Ibrahim Al-neami, Director of Training and Scholarship Administration MOH , GIZAN KSA

A. Venue:King Fahd Central Hospital Training Center Abu Arish, Jazan, Kingdom of Saudi Arabia

B. Date:To be determined Day : Preferably Sunday, the first working day of the week

C. Duration:One day (but to be conducted three times to three different groups)

D. Participants:All staff nurses at KFCH including supervisors Expected participants will be grouped in to three Invitations of other participants may be made depending on the decision of management.

E. Facilities Needed:Hall, data player, laptop, whiteboard markers

F. Budget:To be determined by the management Major budget will be on honoraria of speakers and foods

Proposed Training Program To Improve Services Of Staff Nurses

\begin{tabular}{|c|c|c|c|c|}
\hline Time & Activity/Topic & Rationale & Discussant & Expected Outcome \\
\hline $\begin{array}{l}08: 00- \\
08: 30 \\
\end{array}$ & Arrival/Registration & & & \\
\hline $\begin{array}{c}08: 30- \\
08: 40\end{array}$ & $\begin{array}{c}\text { Orientation of the } \\
\text { Activity }\end{array}$ & To get acquainted with the activity. & $\begin{array}{c}\text { Organizer/Conve } \\
\text { nor }\end{array}$ & $\begin{array}{c}\text { Motivation of } \\
\text { Participants }\end{array}$ \\
\hline $\begin{array}{l}08: 40- \\
09: 40\end{array}$ & $\begin{array}{l}\text { First Presentation } \\
\text { Topic: Rights of } \\
\text { the Patients }\end{array}$ & $\begin{array}{l}\text { A well-informed patient becomes } \\
\text { enlightened, thus reducing his/her } \\
\text { anxiety. }\end{array}$ & $\begin{array}{l}\text { Resource } \\
\text { Speaker }\end{array}$ & $\begin{array}{l}\text { Better information of } \\
\text { nurses on how to adopt } \\
\text { patients' rights in a } \\
\text { Islamic community. }\end{array}$ \\
\hline $\begin{array}{l}09: 40- \\
10: 00 \\
\end{array}$ & Breakfast/Snacks & & & \\
\hline $\begin{array}{l}10: 00- \\
11: 00\end{array}$ & $\begin{array}{l}\text { Second Presentation } \\
\text { Topic: Nurse- } \\
\text { Patient Interaction } \\
\text { in a multi-Cultural } \\
\text { Setting } \\
\end{array}$ & $\begin{array}{l}\text { Good nurse-patient interaction } \\
\text { through clear communication results } \\
\text { To development of morale and } \\
\text { confidence. }\end{array}$ & $\begin{array}{l}\text { Resource } \\
\text { Speaker }\end{array}$ & $\begin{array}{l}\text { Acquire knowledge and } \\
\text { approaches of good } \\
\text { nurse-patient interaction } \\
\text { in a multi-cultural } \\
\text { setting; reduction of } \\
\text { communication barriers. }\end{array}$ \\
\hline $\begin{array}{l}11: 00- \\
12: 00\end{array}$ & $\begin{array}{l}\text { Third Presentation } \\
\text { Topic: Knowledge } \\
\text { of Individual } \\
\text { Differences }\end{array}$ & $\begin{array}{l}\text { Significant variations exist between } \\
\text { individuals aside from their } \\
\text { biographical characteristics. } \\
\text { Understanding their reaction time, } \\
\text { preferences, values and health- } \\
\text { related behaviors can bring a better } \\
\text { plan of action/intervention to } \\
\text { patients. }\end{array}$ & Resource Person & $\begin{array}{l}\text { Appropriate approaches } \\
\text { to patient care adopting } \\
\text { observed behaviors } \\
\text { manifested by patients. }\end{array}$ \\
\hline $\begin{array}{l}12: 00- \\
12: 15 \\
\end{array}$ & Prayer & & & \\
\hline $\begin{array}{l}12: 15- \\
13: 15\end{array}$ & $\begin{array}{l}\text { Forth Presentation } \\
\text { Topic: Managing } \\
\text { Anxiety }\end{array}$ & $\begin{array}{l}\text { Anxiety management can be } \\
\text { in the form of psychological, } \\
\text { physical or cognitive approach. } \\
\text { Managing this helps relieve the } \\
\text { nurse from stress. Hence, she an be } \\
\text { more efficient and effective. }\end{array}$ & $\begin{array}{l}\text { Resource } \\
\text { Speaker }\end{array}$ & $\begin{array}{l}\text { Techniques of anxiety } \\
\text { management. }\end{array}$ \\
\hline $\begin{array}{l}13: 15- \\
14: 15\end{array}$ & $\begin{array}{l}\text { Fifth Presentation } \\
\text { Topic: Standard of } \\
\text { Conduct, } \\
\text { Performance and } \\
\text { Ethics for Health } \\
\text { Team }\end{array}$ & $\begin{array}{l}\text { Providing high standard of practice } \\
\text { at all times make the care of people } \\
\text { as the first concern, thus upholding } \\
\text { the reputation of the nursing } \\
\text { profession. }\end{array}$ & Resource Person & $\begin{array}{l}\text { Appropriate approaches } \\
\text { to patients care; treating } \\
\text { people with respect and } \\
\text { dignity and act as } \\
\text { advocate for those who } \\
\text { are cared, helping them } \\
\text { to access relevant health } \\
\text { and social care, } \\
\text { information and } \\
\text { support. }\end{array}$ \\
\hline $\begin{array}{l}14: 15- \\
14: 30\end{array}$ & $\begin{array}{l}\text { Recapitulation/Distr } \\
\text { ibution of } \\
\text { Certificates } \\
\end{array}$ & & $\begin{array}{c}\text { Organizer/Conve } \\
\text { nor }\end{array}$ & \\
\hline $\begin{array}{l}14: 30- \\
15: 00\end{array}$ & Lunch Break & & & \\
\hline
\end{tabular}




\section{Acknowledgement}

The realization of this research is attributed to many people who have extended their hands and hearts. Without them, it could have not been a reality.

Hence, the Principal Researcher:

\section{References}

[1] A. J. Davis, A. Hershberger, L.C. Ghan and J. Y. Lin, (1990). The good nurse: Descriptions from thePeople's Republic of China. Journal of Advanced Nursing, 15, 829-834.

[2] B. Rush and J. Cook, (2006). What makes a good nurse? Views of patients and carers. BritishJournal of Nursing, 15(7), 382-385.

[3] K. V. Smith, and N.. S. Godfrey, 92002). Being a good nurse and doing the right thing: Aqualitative study. Nursing Ethics, 9(3), 301-312.

[4] Jafar A. Alasad and Muayyad M. Ahmad, (2003). Patients' satisfaction with nursing care inJordan.International Journal of Health Care Quality Assurance, vol. 16, no.6. www.emeraldinsight.com.

[5] Beverly Montago. Responsibility of staff nurse jobs. http://enzinearticles.com

[6] Duties of nurses. www.medicalgeek.com

[7] Doris C. Vahey, Linda H. Alken, Douglas M. Sloane, Sean P. Clarke and Delfino Vargas, (2004). Nurse burnout and patient satisfaction. Med Care, 2004 February. Doi: 10.1097/01.mir.0000109126.50398.5a.

[8] MulchandShambhulalSen, (2009). Patients' satisfaction towards health care services. http://papers.ssrn.com=1473782.

[9] M Veera Prasad, S Sarish Kumar, AmitAgrawal, D Rama Mohan, (2013). Level of satisfaction in patients/attendants admitted with traumatic brain injury at an advanced ER/casualty in atertiary care teaching hospital. Journal of Hospital Administration, 2013, vol. 2, no. 2. www.sciedu.ca/jha.

[10] GhonaAbd El-nasser, Nadia Mohamed, ( 2013). Patient satisfactionwith preoperative care andits relationship with patient characteristics. Medical Journal of Cairo University, vol.81, no.2 March 1-10, 2013. www.medicaljournalofcairouniversity.com.

[11] AH Al-Doghaither, (2000). Inpatients satisfactionwith nursing services at King Khalid UniversityHospital, Riyadh, Saudi Arabia. Journal of Family and Community Medicine, 2000. http://www.torna.do.

[12] M. Al Momani and H. Al Korashy, (2012). Patientexperience of nursing quality in a teachinghospital in Riyadh, Saudi Arabia. Iranian Journal of Public Health 2012. 41(8):42-49. http://ijph.tums.ac.ir.

[13] Satisfaction with care-SF (version 11/99). www.promotingexcellence.org.

[14] Laurentina Paler-calmorin and Melchor A. Calmorin, (1997). Statistics in education and thesciences. Rex Book Store, Manila, Philippines.

Appendix A Questionnaire on

\section{Satisfaction Level Of Inpatients On Nursing Care Provided By Staff Nurses At King Fahd Central} Hospital

Patient/Case Number: Sex: Civil Status: Age:

Ward: $\quad$ Number of Hospital Stay:
days

Instruction: Put a circle around the number which represents your answer to each item.

A. How doyou rate the nurses who attended to you during your stay in this hospital regarding:

\begin{tabular}{|c|c|c|c|c|c|c|}
\hline No. & Indicators & Poor & Fair & Good & Very Good & Excellent \\
\hline 1 & $\begin{array}{l}\text { The way they carried out physical examination } \\
\text { (taking vital signs)? }\end{array}$ & 1 & 2 & 3 & 4 & 5 \\
\hline 2 & The way they administered medications? & 1 & 2 & 3 & 4 & 5 \\
\hline 3 & The attention given to your comfort? & 1 & 2 & 3 & 4 & 5 \\
\hline 4 & Their willingness to listen to all your concerns? & 1 & 2 & 3 & 4 & 5 \\
\hline 5 & $\begin{array}{l}\text { The interest they showed to you personally as a } \\
\text { patient? }\end{array}$ & 1 & 2 & 3 & 4 & 5 \\
\hline 6 & The comfort and support they gave you. & 1 & 2 & 3 & 4 & 5 \\
\hline 7 & $\begin{array}{l}\text { Their personal qualities like politeness, respect, } \\
\text { sensitivity, kindness, patience? }\end{array}$ & 1 & 2 & 3 & 4 & 5 \\
\hline 8 & $\begin{array}{l}\text { The information they gave you about your } \\
\text { medical tests }\end{array}$ & 1 & 2 & 3 & 4 & 5 \\
\hline 9 & $\begin{array}{l}\text { The information they gave you about routine } \\
\text { patient care? }\end{array}$ & 1 & 2 & 3 & 4 & 5 \\
\hline 10 & $\begin{array}{l}\text { The information they gave you about your } \\
\text { treatment? }\end{array}$ & 1 & 2 & 3 & 4 & 5 \\
\hline 11 & Their promptness in answering buzzer calls? & 1 & 2 & 3 & 4 & 5 \\
\hline 12 & The time they devoted to you? & 1 & 2 & 3 & 4 & 5 \\
\hline
\end{tabular}


B. How do you rate the other services and care organizations in this hospital relative to the work of the nurses regarding:

\begin{tabular}{|c|c|c|c|c|c|c|}
\hline No. & Indicators & Poor & Fair & Good & Very Good & Excellent \\
\hline 1 & $\begin{array}{l}\text { Exchange of information among health } \\
\text { team?(nurse/doctor/medtech/radiologist) }\end{array}$ & 1 & 2 & 3 & 4 & 5 \\
\hline 2 & $\begin{array}{l}\text { Kindness and helpfulness of the nurse in assisting you to } \\
\text { the laboratories and other hospital personnel? }\end{array}$ & 1 & 2 & 3 & 4 & 5 \\
\hline 3 & Information provided upon admission? & 1 & 2 & 3 & 4 & 5 \\
\hline 4 & Information provided upon discharge? & 1 & 2 & 3 & 4 & 5 \\
\hline 5 & $\begin{array}{l}\text { Speed in providing information about medical tests } \\
\text { results and/or treatment? }\end{array}$ & 1 & 2 & 3 & 4 & 5 \\
\hline
\end{tabular}

Appendix B

Caclculation Of The Correlation Of Ranks On The Indicators Of Satisfaction Level Of Inpatients On The Services Of Staff Nurses In The Wards/Units

\begin{tabular}{|c|c|c|c|c|c|c|c|c|c|c|c|c|}
\hline \multirow[b]{2}{*}{$\begin{array}{c}\text { Ward/Uni } \\
t\end{array}$} & \multicolumn{12}{|c|}{ Indicators (Please see copy of Questionnaire) } \\
\hline & 1 & 2 & 3 & 4 & 5 & 6 & 7 & 8 & 9 & 10 & 11 & 12 \\
\hline FOW & 12 & 9 & 10 & 3 & 8 & 11 & 7 & 6 & 4 & 5 & 1.5 & 1.5 \\
\hline Burns & 12 & 1 & 7 & 2 & 7 & 4 & 9.5 & 1 & 7 & 4 & 5 & 9.5 \\
\hline FMW & 5 & 10 & 12 & 4 & 10 & 7 & 10 & 1 & 3 & 2 & 7 & 7 \\
\hline $\mathrm{OB}$ & 11.5 & 8.5 & 10 & 4 & 6.5 & 2 & 11.5 & 6.5 & 3 & 8.5 & 1 & 5 \\
\hline Pedia-1 & 11 & 8.5 & 8.5 & 6 & 8.5 & 4 & 12 & 1 & 2 & 3 & 5 & 8.5 \\
\hline FNW & 5.5 & 7 & 10.5 & 10.5 & 10.5 & 8 & 4 & 1 & 3 & 2 & 5.5 & 10.5 \\
\hline FHDU & 9.5 & 4 & 9.5 & 4 & 4 & 9.5 & 9.5 & 4 & 4 & 4 & 12 & 4 \\
\hline ENT & 4 & 4 & 4 & 4 & 4 & 9.5 & 12 & 1 & 11 & 9.5 & 7.5 & 7.5 \\
\hline $\mathrm{CCU}$ & 7 & 7 & 7 & 1.5 & 1.5 & 7 & 7 & 12 & 7 & 7 & 7 & 7 \\
\hline$\sum \mathrm{Tj}$ & 101.5 & 70.5 & 89.5 & 51 & 76.5 & 80.5 & 97 & 39.5 & 52.5 & 59.5 & 61 & 70 \\
\hline
\end{tabular}

$=64103$

$\mathrm{W}=\frac{12\left(\sum T j^{2}\right)}{m^{2}(N)\left(N^{2}+1\right)}-\frac{3(N+1)}{N-1}=\frac{12(64103)}{11^{2}(12)\left(12^{2}+1\right)}-\frac{3(12+1)}{12-1}=\mathbf{0 . 1 0 8}$

$\mathbf{d f}=11$

Level of Significance $(\mathbf{0 . 0 5})=19.68$

$\mathrm{X}^{2}=\mathrm{m}(\mathrm{N}-1) \mathrm{W}=11(12-1) 0.108=\mathbf{1 3 . 0 6 8}$

Analysis $=$ Not Significant

Appendix C

Calculation Of The Correlation Of Ranks On The Indicators Of Satisfaction Levelof Inpatients On The Services Of Staff Nurses

\begin{tabular}{|c|c|c|c|c|c|}
\hline \multirow[b]{2}{*}{ WARDS/Units } & \multicolumn{5}{|c|}{ Indicators (Please see copy of Questionnaire) } \\
\hline & 1 & 2 & 3 & 4 & 5 \\
\hline FOW & 3 & 2 & 5 & 4 & 1 \\
\hline DR & 3 & 4 & 2 & 1 & 5 \\
\hline Burns & 3 & 5 & 4 & 1 & 2 \\
\hline FMW & 4 & 5 & 1 & 2 & 3 \\
\hline $\mathrm{OB}$ & 2 & 3 & 4 & 5 & 1 \\
\hline Pedia-2 & 2 & 3 & 4.5 & 4.5 & 1 \\
\hline Pedia-1 & 4.5 & 4.5 & 2 & 3 & 1 \\
\hline FNW & 3.5 & 5 & 1.5 & 3.5 & 1.5 \\
\hline FHDU & 3.5 & 3.5 & 3.5 & 1 & 3.5 \\
\hline ENT & 1 & 4.5 & 3 & 4.5 & 2 \\
\hline $\mathrm{CCU}$ & 3.5 & 3.5 & 3.5 & 1 & 3.5 \\
\hline$\sum \mathrm{Tj}$ & 33 & 43 & 34 & 30.5 & 24.5 \\
\hline$\sum \mathrm{Tj}^{2}$ & 1089 & 1849 & 1156 & 930.25 & 600.25 \\
\hline
\end{tabular}

$=\mathbf{5 6 2 4 . 5}$

$\mathrm{W}=\frac{12\left(\sum T j^{2}\right)}{m^{2}(N)\left(N^{2}+1\right)}-\frac{3(N+1)}{N-1}=\frac{12(5624.5)}{11^{2}(5)\left(5^{2}+1\right)}-\frac{3(5+1)}{5-1}=\mathbf{0 . 1 4 8}$

$\mathbf{d f}=4$

Level of Significance $(\mathbf{0 . 0 5})=9.49$

$\mathrm{X}^{2}=\mathrm{m}(\mathrm{N}-1) \mathrm{W}=11(5-1) 0.148=\mathbf{6 . 5 1 2}$

Analysis $=$ Not Significant 